\title{
REPRESENTAÇÕES SOCIAIS DE TÉRMINO DE RELACIONAMENTOS AMOROSOS EM MÚSICAS DO SERTANEJO UNIVERSITÁRIO
}

SOCIAL REPRESENTATIONS OF ROMANTIC RELATIONSHIP BREAKUPS IN COUNTRY MUSIC SONGS REPRESENTACIONES SOCIALES DE CONCLUSIÓN DE RELACIONES ROMÁNTICAS EN CANCIONES DEL SERTANEJO UNIVERSITÁRIO

\author{
Adriano Schlösser \\ Brigido Vizeu Camargo** \\ Amanda Nogara Marcon ${ }^{* * *}$ \\ Daniela Xavier Morais ${ }^{* * *}$
}

\begin{abstract}
RESUMO
Das etapas de um relacionamento amoroso, o término da relação constitui-se como uma das mais difíceis, e é, muitas vezes, expressa por meio de composições musicais que tratam dos sentimentos provenientes desse rompimento. Dentre os ritmos musicais que abordam esse tema, destaca-se o sertanejo universitário, cujas letras elucidam, em especial, relacionamentos amorosos descompromissados e de curta duração. Diante disso, a investigação das representações sociais difundidas por meio dessas letras se torna relevante para a compreensão do pensamento social acerca dos términos de relacionamentos amorosos. O objetivo deste estudo é investigar as representações sociais de término de relacionamentos amorosos e presentes em cançôes do estilo musical sertanejo universitário. Foram analisadas 211 letras musicais, submetidas à análise lexical no software ALCESTE. Os resultados e análises apontam diferentes sentimentos e comportamentos derivados desse rompimento afetivo, devido a distintos estágios vivenciados desse sofrimento, tanto por parte de quem rompeu a relação quanto de quem foi abandonado, trazendo elementos que vão desde dor, sofrimento, incerteza e desilusão até resignação, felicidade e satisfação com o fim da relação.
\end{abstract}

Texto recebido em 16 de maio de 2013 e aprovado para publicação em 26 de junho de 2015.

Doutorando em Psicologia pelo Programa de Pós-Graduação em Psicologia da Universidade Federal de Santa Catarina (UFSC); mestre em Psicologia pela UFSC; psicólogo; pesquisador associado do Laboratório de Psicologia Social da Comunicação e Cognição (Laccos). Endereço: Rodovia Amaro Antônio Vieira, 2651 - Itacorubi, Florianópolis-SC, Brasil. CEP: 88034-102. E-mail: adriano.psicologia@yahoo.com.br.

* Doutor em Psicologia Social pela École des Hautes Études en Sciences Sociale; coordenador do Laccos; professor no Programa de Graduação e Pós-Graduação em Psicologia da UFSC. Endereço: Universidade Federal de Santa Catarina, Centro de Filosofia e Ciências Humanas, Departamento de Psicologia, Campus Universitário - Trindade, Florianópolis-SC, Brasil. CEP: 88040900. E-mail: brigido.camargo@yahoo.com.br.

*** Graduada em Psicologia pela UFSC; bolsista de iniciação científica no Laccos. Endereço: Rua Desembargador Arno Hoeschl, 254 - Itacorubi, Florianópolis-SC, Brasil. CEP: 88015-620. E-mail: amandanogara@hotmail.com.

${ }^{* * * *}$ Mestranda em Psicologia pelo Programa de Pós-Graduação em Psicologia da Universidade Federal de Santa Catarina (UFSC); psicóloga. Endereço: Rodovia Amaro Antônio Vieira, 2155 - Itacorubi, Florianópolis-SC, Brasil. CEP: 88034-101. E-mail: daniela10xm@gmail.com. 
Palavras-chave: Representações sociais. Relacionamentos amorosos. Término. Música.

\section{ABSTRACT}

When it comes to the stages of a romantic relationship, the breakup moment is one of the most difficult for people to experience, and is often expressed through musical compositions, which talk about feelings related to this rupture. Among the musical rhythms that talk about this theme one particularly stands out the Country \& Western , whose lyrics elucidate, especially, love relationships and uncommitted short-lived. Therefore, the research of social representations disseminated through these lyrics is relevant to social understand about loving relationship breakups. The aim of this study was to investigate the social representations of romantic relationship breakups present in songs of the musical style called Country \& Western. For this study, 211 lyrics were analyzed, submitted to lexical analysis in the ALCESTE software. The results and analysis demonstrate varied feelings and behaviors derived from this breakup, owing to the different stages of the suffering, experienced either by both, the one who terminated the relationship and who was abandoned, bringing elements ranging from pain, suffering, uncertainty and disappointment to resignation, happiness and satisfaction with the relationship which was terminated.

Keywords: Social representations. Romantic relationships. Breakup. Music.

\section{RESUMEN}

En las etapas de una relación amorosa, el término de la relación es una de las experiencias más difíciles, y a menudo se expresa a través de composiciones musicales, que tratan sobre los sentimientos de esta interrupción. Entre los ritmos musicales que abordan este tema destaca el sertanejo universitario, cuyas letras tratan, especialmente, las relaciones amorosas sin compromiso y de corta duración. El propósito de este estudio fue investigar las representaciones sociales del término de las relaciones amorosas, presentes en canciones del estilo musical sertanejo universitario. Se analizaron 211 letras, presentada al análisis de léxico del software ALCESTE. Los resultados y los análisis muestran diferentes sentimientos y comportamientos derivados de este rompimiento afectivo, debido a las diferentes etapas experimentadas en ese sufrimiento, tanto por los que rompieron la relación, cuanto por quien fue abandonado, con elementos que van desde el dolor, el sufrimiento, la incertidumbre y la decepción, hasta la resignación, la felicidad y la satisfacción con el fin de la relación.

Palabras clave: Representaciones sociales. Relaciones amorosas. Término. Música. 


\section{INTRODUÇÃO}

0 fenômeno da música se manifesta no cotidiano do ser humano. As pessoas, em seu dia a dia, mantêm contato com a música: nas ruas, na tevê, em filmes, novelas, teatros, propagandas comerciais e políticas, shows, concertos, entre outros locais, a música se faz presente. Em seu ritmo e letra, o ser humano compartilha sentimentos, valores, sensações, conteúdo de ideias, disposições e resoluçóes que retratam tanto características individuais quanto compartilhamento de valores coletivamente construídos.

A música é apontada como a mais social das manifestaçôes humanas, uma vez que permite que as pessoas se integrem a uma fonte sonora que compartilha um mesmo fato musical, tornando-a uma manifestação cultural e socialmente partilhada. Como fenômeno social, esta abarca sentidos e funçôes específicas em diferentes sociedades, ao longo do percurso da humanidade, variando de acordo com as especificidades socioculturais de cada período e corpo social (Cunha \& Cruz, 2011). Segundo Ilari (2006), a música, na sociedade ocidental, relaciona-se diretamente às relaçôes interpessoais, associando-se tanto a situações corriqueiras do cotidiano (como contar estórias, vender produtos, dançar, rezar, etc.) quanto em cenários que envolvem atração interpessoal (Huron, 1999).

Considerando que uma música é formada por uma aglutinação de melodia, letra, ritmo e harmonia, relevando emoções, sentimentos, pensamentos e demais cognições, as letras de música têm vital importância na transmissão de valores, significados e saberes compartilhados socialmente por determinados grupos. Para Medina (1973), as letras musicais transmitem importantes compreensóes de valores tradicionais ou novos que estão vigentes para determinados grupos, atuando como meio de transmissão desses valores, o que faz com que a música se torne um meio de institucionalizar o conhecimento da situação social atual, trazendo também uma identidade coletiva a esse corpo social.

Nesse quesito, a música, como manifestação de arte, não apenas transmite valores, mas desponta como uma forma de o indivíduo reconhecer-se em meio a um grupo. A partir do momento em que as pessoas se apropriam dos conteúdos trazidos pelas letras musicais e, ou, de determinado gênero musical, a música passa a ter significância individual, traduzindo visões de mundo, sentimentos e valores que, mesmo individuais, passam a ser compartilhados coletivamente, de acordo com o histórico de cada indivíduo (Budag, 2009).

Alguns estudos têm tentado analisar a conexão entre a música e as dimensões social e afetiva (Cunha \& Cruz, 2011; Ilari, 2006; Janotti Júnior, 2004; Juslin \& Sloboda, 2001; Krumhansl, 1997). No que compete à dimensão social, o aspecto central é o conteúdo comunicacional da transmissão de crenças, valores 
e julgamentos que compõem o universo cotidiano. Já a dimensão afetiva pressupóe que os sentimentos induzidos pela música têm significativo efeito no comportamento social e são adequados a uma combinação de crenças individuais e grupais.

Para que determinado gênero musical passe a sinalizar os valores e compreensões da realidade do segmento que deseja atingir, faz-se necessário que aborde temáticas que fazem parte do cotidiano da população e retratam as problemáticas do dia a dia, como os relacionamentos amorosos, por exemplo. É nessa etapa que adentra o gosto musical. Ele pode ser compreendido como a sintonia que o indivíduo faz com determinados valores presentes em um ou mais gêneros musicais, conferindo-lhes positividade em detrimento de outros (Janotti Júnior, 2004). Dessa forma, gostar de determinado tipo de música aparece como uma forma de portar-se e reconhecer-se diante do mundo, além de pressupor a expressão de determinados afetos, modos de compreensão da realidade, posicionamentos e ações que são similares ao indivíduo, presentes no percurso narrativo das letras musicais.

Entre os diversos estilos que permeiam o universo musical e que abordam a temática dos relacionamentos amorosos, mais precisamente o término dessas relações, esta pesquisa buscou investigar o estilo denominado "sertanejo universitário". A música sertaneja tem apresentado mudanças, incorporando novos elementos à sua estrutura, tais como instrumentos elétricos (bateria, guitarra, contrabaixo) e novos ritmos (Santos, 2010). Somando-se a isso, cantores com carreiras "solo" ou em duplas que compõem essa categoria apresentam novos perfis estilísticos com apelo comercial, tais como roupas de grife, cabelo bem cuidado e moderno, ocupando o lugar do que antes dos anos 2000 era o espaço dos chapéus, botas e fivelas (Zan, 2008).

O sertanejo denominado "universitário" é um fenômeno recente, iniciado no Brasil. Com público cada vez maior, composto por pessoas de diferentes classes econômicas, aborda em suas letras temas como amor, traição e relacionamentos, indicando grande alusão ao amor descompromissado, aos relacionamentos breves, à diversão e à alegria, com ritmo contagiante (Bastos, 2009). O amor, como tema comum, surge de diversas maneiras, em meio às explicaçôes dos sentimentos de alguém por quem se está apaixonado, à tristeza do amor não correspondido, à incapacidade de esquecer e aos sentimentos derivados do término de um relacionamento.

O sertanejo universitário iniciou-se com o lançamento do primeiro disco da dupla César Menotti \& Fabiano, em 2004, tornando a dupla precursora do gênero musical (Santos, 2010). Os cantores presenteavam estudantes universitários com cortesias para seus shows, o que conferia um novo elemento musical ao sertanejo, 
culminando na terminologia "universitário" (Santos, 2010). Além do estilo sertanejo, o sertanejo universitário mistura estilos musicais, como pop, rock e axé, o que, para Bastos (2009), torna-o um modelo musical pop, uma vez que ritmo e intensidade musical passam a influenciar o estado emocional dos ouvintes, o que contribui para que sejam alcançados sentimentos, como alegria ou tristeza, que as músicas elucidam (Silva, 2004).

A música traz em seu cerne os valores, crenças, pensamentos e práticas sociais construídos e compartilhados por determinados grupos, servindo também como mediadora nos processos de interação das pessoas. Diante disso, este trabalho terá como base teórica a teoria das representações sociais (TRS) (Moscovici, 1976; 1978; 2012). As representações sociais (RS) são construções sociais do pensamento originadas no senso comum, que, interativamente, são formadas na dinâmica das relações sociais historicamente circunscritas, num determinado tempo e em determinada cultura (Moscovici, 1978; 2012; Vala, 1996; Jodelet, 2001). Assim, sentidos, conceitos, crenças e percepções que podem ser percebidos nos discursos cotidianos são componentes fundamentais na compreensão das representações sociais, uma vez que, por meio destas, é possível constatar como os sujeitos concebem determinado fenômeno e agem diante dele. As RS variam de acordo com o contexto de relaçôes sociais no qual estão inseridas e dão sentido à realidade dos grupos sociais, influenciando suas visões de mundo (Doise, 1985; Jodelet, 2001).

Segundo Abric (1998), as RS têm a função de explicar aspectos importantes da realidade, definir a identidade grupal, orientar práticas sociais e justificar ações e tomadas de posição depois que estas são concretizadas. Elas são construídas e difundidas por meio da interação entre os indivíduos, mediante práticas de comunicação do cotidiano (Moscovici, 2012). Nessa perspectiva, uma representação social possibilita aos indivíduos interpretar e conferir sentido a determinados aspectos da realidade, agir diante desta e tomar o lugar do objeto social a que se refere, transformando-se ela mesma na realidade (Wachelke $\&$ Camargo, 2007).

Uma representação não apenas dá acesso a explicações sobre a realidade, mas fixa sentidos que garantem a identidade e unidade de grupos sociais (Jodelet, 2001). As letras musicais, ao serem ouvidas, passam pelo processo de percepção, seleção e reconstrução temática (Schlösser, 2014), uma vez que os conteúdos e sentidos presentes nas composições são reapropriados e representados pelo indivíduo e grupo ao qual pertence, de acordo com a familiaridade e não familiaridade com o assunto. $\mathrm{O}$ conteúdo é reconstruído em seu sistema cognitivo, integrado aos valores e dependente de sua história individual e dos grupos sociais e ideológicos que o circundam (Abric, 1998). 
As RS, formadas com base na comunicação, sustentam-se por dois processos sociocognitivos intrinsecamente ligados: objetificação e ancoragem (Moscovici, 1981). São formas específicas em que as $R S$ instituem mediações, materializando uma construção simbólica de um determinado grupo e possibilitando sua concretude em espaços sociais. Também são processos cognitivos socialmente regulados, possibilitando que um conhecimento estranho seja incorporado a uma rede de categorias já existentes para o indivíduo, viabilizando, assim, comparar o novo conhecimento com algo já conhecido, mediante esquemas outrora elaborados (Vala, 2006).

A objetificação consiste na transformação do novo objeto, que é abstrato, em algo concreto, por meio de imagens ou ideias (Moscovici, 1981; Vala, 2006). Há uma síntese de diversos conteúdos estranhos a uma realidade familiar que leva à reprodução de um conceito em uma imagem, à sua cristalização e provável modificação das condutas e relações sociais (Moscovici, 1984). Já a ancoragem é refletida como o processo no qual as informaçôes sobre um dado objeto social são classificadas em relação a estruturas de saberes já existentes. Assim, o sujeito interpreta o novo objeto de acordo com o contexto, ou seja, o novo conhecimento é amparado pelos conhecimentos já assimilados, e está relacionado a uma memória coletiva (Moscovici, 1981; Vala, 1996).

Embora uma representação se ancore em saberes preexistentes, ela permanece como um guia para a ação, que é sempre contextualizada na realidade social, definindo-se assim como um produto e um processo (Jodelet, 1986). Ela é produto, pois traz conteúdos sobre objetos sociais com maior e menor estabilidade, e é processo, pois está sempre em processo de construção e completude.

Entre os temas trazidos nas canções musicais, o término de relacionamentos amorosos é recorrente. A temática que envolve relacionamentos amorosos é uma das principais questóes que se apresentam no discurso cotidiano das pessoas, e seu término remete a uma gama de emoções, sentimentos e valores que são observados nos discursos sociais.

De acordo com Marcondes, Trierweiter e Cruz (2006), a separação em relacionamentos amorosos caracteriza-se como a quebra de vínculos afetivos, sexuais, emocionais e materiais, sendo essa uma situação experimentada pela maioria das pessoas. Para Bronini, Esiquiel, Lazarini, Parada e Almeida (2010), o fim de um relacionamento amoroso traz, de forma geral, uma série de sentimentos que perpassam o estado emocional do indivíduo que "perde" seu (sua) parceiro(a), tais como culpa, luto, solidão, inveja, ciúmes, raiva, insegurança, carência, saudade, dor, desejo de vingança, entre outros. Em alguns casos, a separação pode ser vivenciada por uma sensação de alívio, embora predominem a incerteza e a insegurança advindas desse rompimento. 
Outra característica que pode diferir nos sentimentos decorrentes do término de um relacionamento amoroso seria advinda de quem é o responsável pelo término, tendo em vista que pessoa "deixada" tende a sofrer em maior escala. Já o indivíduo que rompe a relação pode apresentar a sensação de alívio e, ou, euforia, por meio da libertação de um vínculo que possivelmente lhe trazia infelicidade. Posteriormente, podem surgir os sentimentos de dor, culpa e tristeza, mediante as lembranças dos bons momentos vivenciados pelo casal (Bronini, Esiquiel, Lazarini, Parada \& Almeida, 2010), além de sentimentos como raiva e frieza, ao focar os aspectos ruins do relacionamento, servem como anestésico da dor do término, como forma de autoconvencimento de que a perda não foi grande.

O término de relacionamentos amorosos tem se tornado mais frequente mediante transformações nos princípios, valores e condutas que permeiam as normas sociais da atualidade (Goulart, Lazarini, Bronini, Parada, Pratta \& Almeida, 2011). Esse fenômeno pode ser observado por meio das expressóes musicais em diversos gêneros, em especial o "sertanejo universitário", que aborda com muita ênfase o término de relacionamentos. Diante disso, esta pesquisa propõe a investigação das representações sociais de término de relacionamentos amorosos presentes em letras de músicas do gênero musical "sertanejo universitário" que discorram sobre o tema.

\section{MÉTODO}

Este estudo caracteriza-se pela natureza documental e exploratória, uma vez que envolve documentos que não sofreram tratamento analítico. Procura identificar dados factuais nos documentos com base em questôes de interesse e favorece a observação do processo de maturação ou evolução de indivíduos, grupos, conceitos, conhecimentos, comportamentos, práticas, etc. (Cellard, 2008; Sá-Silva, Almeida \& Guindani, 2009).

Foi investigado o acervo musical do site Letras de Música, cuja busca indicou 1.670 letras musicais do gênero sertanejo universitário. Entre elas, 183 se qualificaram por abordarem exclusivamente a temática do término de relacionamentos amorosos. Cabe ressaltar que a escolha do site se baseou na ampla e constante difusão e atualização das letras de músicas publicadas.

As letras de músicas correspondiam a 13 cantores ou duplas que compõem o estilo musical sertanejo universitário: as duplas João Bosco e Vinícius (27 músicas), Marcos e Belutti (25 músicas), João Neto e Frederico (24 músicas), Jorge e Mateus (21 músicas), Guilherme e Santiago (19 músicas), Fernando e Sorocaba (19 músicas), Hugo Pena e Gabriel (15 músicas), Maria Cecília e 
Rodolfo (9 músicas), Thaeme e Thiago (6 músicas), Humberto e Ronaldo (4 músicas); e os cantores Luan Santana (18 músicas), Gusttavo Lima (16 músicas) e Michel Teló (8 músicas).

Foram observadas também as variáveis sexo dos artistas e posicionamento em relação ao término do relacionamento. Entre as 211 letras de músicas, 196 são interpretadas por cantores ou duplas exclusivamente do sexo masculino, seguidas por 15 letras interpretadas por duplas denominadas mistas, nas quais há uma pessoa do sexo feminino e uma do sexo masculino. Não houve nenhum cantor ou dupla exclusivamente do sexo feminino. Quanto ao posicionamento em relação ao término do relacionamento, as letras foram classificadas em "terminou o relacionamento" e "término do relacionamento realizado pelo outro", sendo que 128 letras abordaram o ponto de vista de quem teve seu relacionamento encerrado pelo outro, e 83 se reportaram ao ponto de vista de quem teve a iniciativa de encerrá-lo.

Os dados foram submetidos a uma análise lexical de conjuntos de segmentos de texto, a partir da qual foi realizada uma classificação hierárquica descendente (CHD), por meio do programa informático Analyse Lexicale par Contexte d'un Ensemble de Segments de Texte - ALCESTE (Camargo, 2005).

\section{RESULTADOS}

Os dados obtidos nesta pesquisa foram analisados com base em um corpus cujo conteúdo está relacionado a letras de músicas do estilo sertanejo universitário que abordaram a temática dos términos de relacionamentos. O corpus foi constituído, em sua maior parte, de respostas curtas, compostas por 15 linhas em média, e foi submetido à análise lexical parametrada, na qual cada letra musical foi considerada uma unidade de análise.

O corpus foi composto por 211 UCE (unidades de contexto elementar), as quais continham 2.560 palavras analisáveis (indicadoras de sentido) que ocorreram 21.816 vezes, sendo a média de ocorrência de 9 vezes por palavra. A análise hierárquica descendente reteve 89,57\% das UCE do corpus (189 das 211 UCE), organizadas em quatro classes, como indica a figura 1. Ela contém: a) o nome do corpus e a quantidade de UCE retidas nele; b) o nome das classes e o número de UCE que a compõem; c) a descrição das classes e das palavras que mais se associaram a ela, em função do ${ }^{2} \mathrm{e}$ da frequência média de ocorrência das palavras. $\mathrm{O}$ corpus sofreu uma primeira partição em dois subcorpus, indicando as classes 1 e 2 em oposição às classes 3 e 4 . A partir disso, houve uma segunda partição, opondo as classes 1 e 2. E, por fim, ocorreu uma terceira partição, originando as classes 3 e 4 . 
Figura 1. Dendograma de classes sobre as impressões dos términos de relacionamentos encontrados em músicas do estilo sertanejo universitário

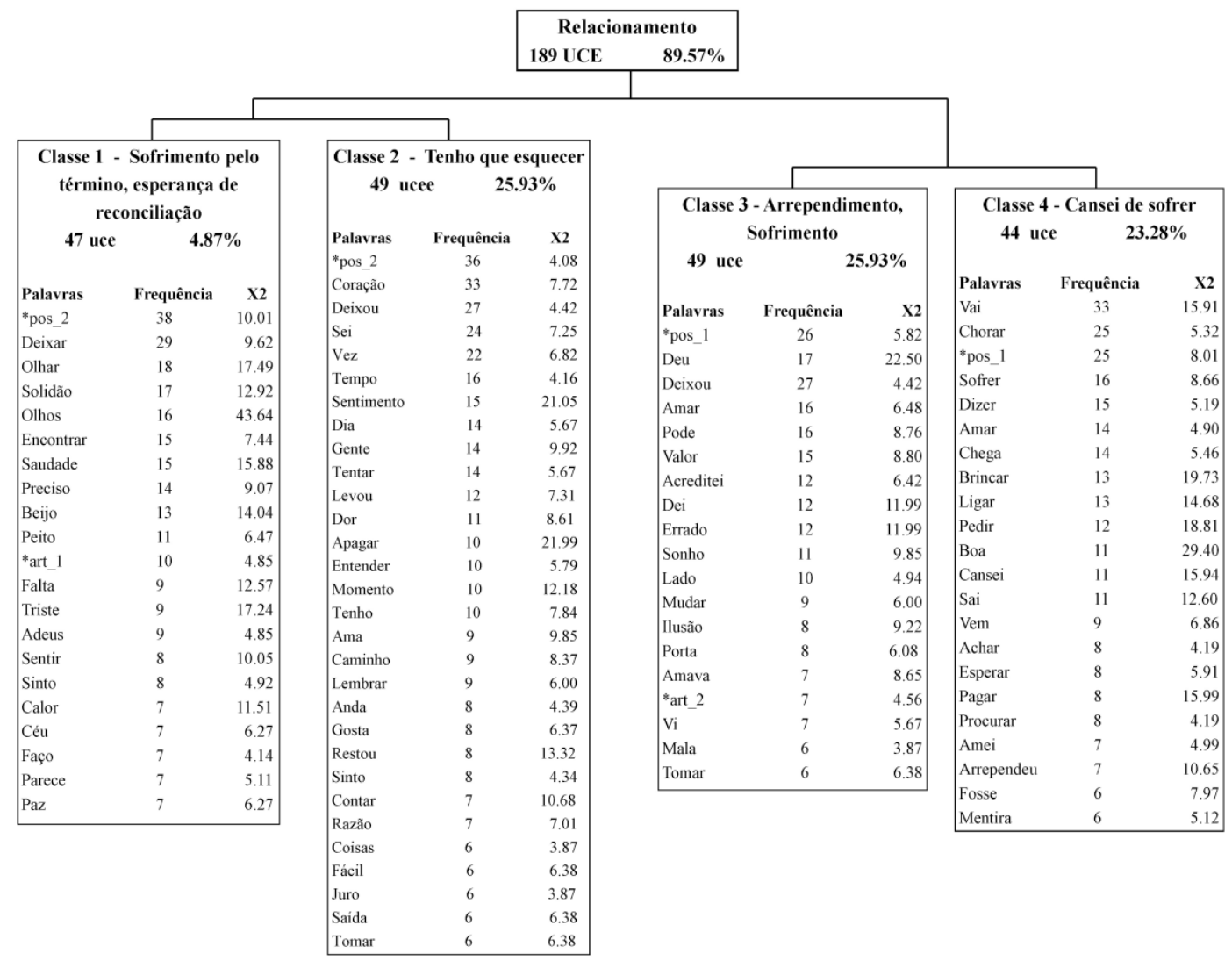

Fonte: Elaborado pelos autores.

Passa-se a apresentar as unidades de contexto elementar características de cada uma das classes, sendo esses fragmentos que elucidam a coocorrência de palavras no corpus. Pode ser observado, o conjunto de UCE características da classe 1 (47 UCE, 24,87\% das UCE classificadas), intitulada "Sofrimento pelo término, esperança de reconciliação", agrupa referências que demonstram sofrimento e saudade da pessoa que não optou pelo fim do relacionamento, e sim seu (sua) parceiro(a), e que nutre esperanças de uma possível reconciliação, como exemplificado nos excertos que seguem. 
Meu amor, não termine assim. Eu te amo demais pra desistir, continuo a viver essa paixão em mim. Ah, me faz falta o teu sorriso, você é tudo o que eu preciso. Quero de volta a minha paz, porque quem ama assim não esquece nunca mais. Você foi embora sem me dizer nada, só deixou saudade em seu lugar (UCE 209). (Guilherme \& Santiago, 2008)

Quando olho as estrelas no céu, lembro teus olhos de cristal e tua boca de mel. Sentia os seus lábios se encontrando com os meus, não consigo acreditar como tudo se perdeu. Então, deixa eu te mostrar porque tô sofrendo assim [...] é que meu peito machucado só cura com você do meu lado (UCE 116) (Luan Santana, 2010).

A classe 2 (49 UCE, 25,93\% das UCE classificadas), intitulada "Tenho que esquecer", reúne elementos indicativos que fazem alusão a indivíduos que não optaram pelo término do relacionamento e sim seu (sua) parceiro(a), mas que vêm buscando conformar-se com a situação, esquecer o ocorrido, elaborar o luto e seguir a vida. Em contraponto à classe 1, não foram verificados elementos que indicassem um possível retorno ao relacionamento findado. Contudo, ainda se fazem presentes a saudade e os sentimentos de tristeza advindos do cessar a relação amorosa.

Sei que meus pensamentos insistem em te perseguir. Mas estou me acostumando aos poucos sem você aqui. Veja bem, mas que bobeira a minha, eu pensar que um dia me amou igual. Tudo bem, o tempo vai passando, e vou me conformando que nada foi real (UCE 130) (Marcos \& Bellutti, 2009)

"Então pode ir, mas vai na certeza que vai de uma vez. Esquece essa vida o que a gente já fez, que meu coração vai levando com jeito” (UCE 168) (Marcos \& Belutti, 2011)

A classe 3 (49 UCE, 25,93\% das UCE classificadas), intitulada "Arrependimento, sofrimento", opóe-se às classes 1 e 2 , uma vez que seus elementos apontam sentimentos advindos de quem terminou o relacionamento amoroso. Ela tem segmentos de texto que exteriorizam o sofrimento de quem terminou o relacionamento, mas se arrependeu dessa ação, traduzindo-se na forma de saudade e desejo de reatar a relação.

"Vacilei, me perdi, você estava bem aqui, mas eu não dei valor. Vacilei, vou sofrer, posso até enlouquecer, volta, por favor" (UCE 42) (Fernando \& Sorocaba, 2008) 
“[...] mas só me dei conta agora que eu te perdi. Blefei, joguei, fiz o que fiz. Paguei dobrado, fui infeliz. Tá machucando agora. Acreditei demais em mim, quis ser o bom e me perdi. Brinquei de ir embora, eu te perdi” (UCE 129) (Thaeme \& Thiago, 2012)

"Tudo errado. Eu joguei os meus sonhos para o alto no momento em que te deixei. Quatro anos de paixão só serviram pra mostrar que não se brinca com o coração [...]. A gente pode voltar, deve haver algum jeito" (UCE 32) (Fernando \& Sorocaba, 2010)

Essa classe também apresenta conteúdos que retratam o término do relacionamento amoroso derivado de uma relação conflituosa, no qual um dos membros não valorizou o(a) companheiro(a). Nesse caso, verifica-se que o término do relacionamento não foi motivado pela falta de sentimentos amorosos por parte de quem terminou a relação, mas sim devido a comportamentos negativos do(a) parceiro(a). "Quem tanto te amava e estava sempre ao seu dispor, te valorizava, mas você nunca me deu valor. Perdeu, perdeu, perdeu, perdeu" (UCE 40) (Fernando \& Sorocaba, 2010)

Eu dei mais uma chance pra você e acreditei que dessa vez podia dar certo, que a vida te fez aprender que o tempo fez você crescer e sair de uma vez do deserto. Mas nada disso aconteceu, você continua sendo a mesma que eu conheci um dia [...]. Agora vai ser assim, eu quero esse amor bem longe de mim (UCE 140) (Marcos \& Belutti, 2011)

A classe 4 (44 UCE, 23,28\% das UCE classificadas), intitulada "Cansei de sofrer”, reúne elementos referentes ao indivíduo que rompeu um relacionamento amoroso que estava lhe causando infelicidade. Nesta classe, observa-se que o fim do relacionamento traz consigo alívio pelo fim, sem desejo de retornar à relação.

"Sai! Eu não te quero mais, não vem com esse papinho, eu não volto atrás. Se liga eu já falei, vacilou demais. Brincou demais com o meu amor e só me fez sofrer, já consegui te esquecer" (UCE 41) (Fernando \& Sorocaba, 2008)

"Chega, eu não quero mais ficar te esperando, pra mim tanto faz. Chega, um longo tempo se passou, é hora da despedida desse nosso amor. É um absurdo você achar que é dona de mim. Tá tudo errado, amor bagunçado, eu não tô a fim” (UCE 66) (Jorge e Mateus, 2008)

Além disso, também agrupa referências de que o parceiro busca reatar o relacionamento, mas o que a pessoa que terminou a relação busca seria "curtir a vida de solteiro". "Foi se aventurar e agora ficou só, ai que dó, ai que dó. Eu 
tô aqui festando e você na pior, ai que dó, ai que dó. Se hoje vive chorando lembrando de nós ai que dó! Ai que dó o quê? Eu quero ver você sofrer" (UCE 95) (Thaeme \& Thiago, 2012)

"Só me fez sofrer, me fez chorar, me magoou. E agora você vem dizer pra eu te perdoar, não precisa chorar, já consegui te esquecer” (UCE 41) (Fernando \& Sorocaba, 2008)

"[...] então só para te avisar, lembra da sua amiga a Camila, aquela gata, baita avião. A danada foi bandida, esqueceu que é sua amiga e também passou na minha mão. Nada pessoal” (UCE 38) (Fernando \& Sorocaba, 2010)

\section{DISCUSSÃO}

O relacionamento amoroso ocorre mediante o desenvolvimento de um sentimento de amor por determinado indivíduo, sendo tal sentimento uma das mais intensas emoções humanas (Sterberg \& Grajek, 1984), e um tipo específico de atração interpessoal (Alferes, 2004), considerando o amor como um fenômeno dialético, este também se liga à dor ou à tristeza, mediante a ausência de reciprocidade e advindo do término desse relacionamento (Nóbrega, Fontes \& Paula, 2005). Quando ocorre o término de relacionamentos afetivos, surgem, em grande parte das pessoas, algumas alteraçôes dos estados psíquicos e emotivos, advindos da dor da separação. Essa alteração de origem emocional pode ser fisicamente sentida, tamanha carga afetiva nela imposta, tais como sensação de sufocamento e, ou, peso, falta de ar, dor no peito, perda da realidade e demais estados depressivos (Guedes, Monteiro-Leitner \&, Machado, 2008; Marcondes, Trierweiter \& Cruz, 2006).

A música funciona como mediadora das interaçôes e da comunicação entre as pessoas (Maffesoli, 2007). Ao se configurar como parte da história pessoal, tais canções trazem à tona sentimentos, emoções e memórias referentes às vivências afetivas dos ouvintes. Os temas musicais se tornam objetos relevantes quando seu significado é familiar e faz parte da realidade social. Com base na interpretação dos indivíduos e grupos, os conteúdos presentes nesses temas são reconstituídos e integrados aos sistemas de crenças já existentes, sob a forma de representações sociais.

Nos conteúdos presentes nas letras sobre término de relacionamentos amorosos, verifica-se a elaboração e compartilhamento de regras específicas para diferentes modalidades de término, guiando práticas e justificando posicionamentos, por exemplo: manifestar sofrimento e arrependimento por ter traído ou cometido algum ato negativo para o relacionamento; não demonstrar sentimento de 
tristeza diante do(a) parceiro(a) que terminou o relacionamento ou que cometeu algum comportamento inadequado; comportar-se de forma alegre e envolver-se em novos relacionamentos, visando a demonstrar que superou o relacionamento; entre outros.

O aspecto comunicacional presente nas representações sociais merece destaque nesta temática. Para Jodelet (2001), a comunicação de massa é central na construção e difusão de RS, uma vez que é por meio dos veículos de comunicação que os conteúdos são difundidos e chegam aos grupos sociais, fomentando os conhecimentos, crenças e atitudes, bem como possíveis recriações de conceitos. Considera-se que a música, como veículo de comunicação de massa, tem importante papel na construção de representações sociais de objetos sociais relevantes para as vivências sociais.

Os resultados apontam os conteúdos das músicas como produto e processo comunicacional com intuito de proteger e legitimar valores morais e interesses sociais. Diante disso, os processos de objetificação e ancoragem são evidenciados. Tendo em vista que o processo de objetificação busca transformar algo abstrato em concreto (Moscovici, 1981), diversas imagens se apresentam nas letras musicais como forma de materializar os sentimentos desencadeados em situações de término de relacionamento amoroso. Complementando isso, o processo de ancoragem se manifesta sob a forma de categorizaçôes, tornando familiar o não familiar (Moscovici, 1981). Tais proposições são evidenciadas na ocorrência de algumas palavras que representam essa perspectiva, tais como "solidão", "peito", "triste", "dor" e "chorar".

Esses sentimentos, advindos da perda da pessoa amada, são apresentados nas cançôes do sertanejo universitário e passam a dar sentido concreto ao término do relacionamento, refletindo sentimentos comuns na perda de um amor. A dor e a tristeza manifestam-se concretamente na realidade social, ancorando sua dimensão abstrata a elementos familiares e concretos associados a sofrimento. Antagonicamente, quando o término de relacionamento não é caracterizado pelo sofrimento, mas como forma de romper com uma situação desagradável, denotando alívio, a formação das representações se objetifica e ancora em imagens e categorias positivas. Festas, sentimentos e comportamentos que denotam alegria, demonstração de desprezo pelo sofrimento alheio e busca de novos(as) parceiros(a) são as imagens que se materializam nesta situação específica, ancorando-se sob a forma de práticas sociais que não associam o término do relacionamento amoroso ao luto e à tristeza, mas sim a sentimentos alegres.

O produto das representações sociais se constitui de todas as informações, saberes e crenças que constroem, definem e sustentam uma representação de 
um objeto social relevante para grupos específicos, de modo a dar sentido a sua realidade social. Mesmo estável, ela é constantemente reconstruída nas interações humanas, trazendo assim sua dimensão processual. Observou-se, como produtos das RS de término de relacionamentos amorosos, algumas particularidades, de acordo com as classes provenientes da classificação hierárquica descendente.

$\mathrm{Na}$ classe 1, o sofrimento diante do término do relacionamento amoroso, advindo da pessoa que não foi responsável pelo fim da relação. Apresenta-se ainda uma não aceitação dessa nova situação, fomentada pelo desejo e crença de reconciliação do casal. Os resultados dessa classe vão ao encontro do que discorre Bronini et al. (2010) sobre os possíveis sentimentos desencadeados com o fim de um relacionamento afetivo, como sofrimento, insegurança, dor, carência e saudade.

A classe 2 traz elementos que denotam a elaboração do luto derivado do término do relacionamento bem como o reinício da vida individual, embora ainda se apresente sentimentos tristes também advindos de um relacionamento findado pelo(a) parceiro(a). Ducatti (2005) aponta a separação como movimento inverso da intimidade, uma vez que há o afastamento de uma pessoa com a qual foi construído um vínculo intenso, mediante o envolvimento emocional. Logo, a quebra desse vínculo resultaria num cessamento da intimidade do casal, dando lugar ao processo de redescoberta da individualidade (Andrade, 2009). A dimensão representacional aponta que os conteúdos se ancoram em estratégias de superação, por meio de comportamentos que se diferenciam das vivências com a pessoa amada.

Dependendo de quem for o responsável pelo término da relação, os sentimentos derivados desse rompimento podem ser diferentes bem como as representações sociais. Mesmo podendo trazer dor a ambas as partes, as pessoas que percebem a si mesmas como abandonadas costumam sofrer mais (Marcondes, Trierweiter $\&$ Cruz, 2006). As letras musicais apontam elementos representacionais que se objetivam e ancoram em imagens que associam o término à experiência da dor e sofrimento, trazendo analogias como "dor no peito", "estou morrendo por dentro" ou "minha vida perdeu o sentido sem você". O indivíduo que terminou, uma vez que teve motivos para tal, pode trazer consigo sentimentos de alívio e euforia, trazidos pela sensação de liberdade diante de uma relação que lhe trazia desgosto, e a renovação de uma nova etapa. Podem surgir lembranças dos bons momentos juntos, tristeza pelo que a relação poderia ter sido, reflexão sobre os motivos pelos quais o relacionamento não se manteve, bem como tristeza, culpa e possíveis sentimentos de retorno. Nesse caso, as letras musicais trazem novamente elementos representacionais associados à alegria, diversão, festa e relacionamentos breves. Além disso, nos elementos presentes nas composições 
da classe 2, as funções de orientação e justificativa das RS se materializam sob forma de apresentar práticas e justificá-las, como a vingança sob forma de novos relacionamentos amorosos, normalmente sem vínculo emocional estável, como estratégia de demonstrar que o relacionamento anterior já foi superado, por exemplo.

Nesse quesito, as letras musicais podem ser compreendidas como forma de conhecimento teórico e prático, articuladas às RS. É teórico, pois transmitem conhecimentos específicos sobre temas associados a experiências do cotidiano, e prático, pois guia e justifica comportamentos e posicionamentos diante de objetos socialmente relevantes, transformando saberes em conhecimentos práticos.

Evidenciaram-se as características levantadas nas classes 3 e 4, compostas por cançôes que traziam letras de pessoas que terminaram o relacionamento amoroso. Enquanto a classe 3 trouxe conteúdos que apontam para o arrependimento da relação findada ou que a motivação principal do término não foi a falta de sentimento amoroso, mas devido a algum comportamento feito pelo parceiro (a), a classe 4 traz justamente a euforia da nova condição de solteiro, sem desejar o retorno à antiga situação, inclusive como vingança.

Quando o término do relacionamento se apresenta como a solução para um problema do casal, este nem sempre é vivenciado com alívio de uma situação desgastante, mas passa a mobilizar sentimentos de insegurança e incertezas diante das mudanças (Marcondes, Trierweiter \& Cruz, 2006).

Outro ponto importante verificado neste estudo apresenta-se nos conteúdos representacionais presentes nas classes, que se manifestam por intermédio de demonstraçôes de afetividade. A dimensão afetiva está na raiz, estrutura e interface em que a representação social se aloca ao permitir, por meio da linguagem, a comunicação humana das relações cotidianas (Arruda, 2007). Nesse quadro, a afetividade apresenta-se como atributo central nas RS da música (nesse caso, sobre término de relacionamentos amorosos), tendo em vista a carga afetiva que essa vivência apresenta.

Com base na noção de que afetos instigam ações e são sensações vivenciadas por meio dos sentimentos, e que as RS são um saber prático constituído pelas experiências, guiando as ações e determinando os modos de vivências de indivíduos e grupos, sustenta-se que esse conhecimento, para ser posto em prática, necessita estar dotado de cargas afetivas (Rouquette, 2005).

A dimensão afetiva das RS de término de relacionamentos amorosos presentes nas músicas se manifesta nos processos de objetificação e ancoragem, apresentados por meio elementoscom fortecarga afetiva etambém comportamentosemocionais, como ao falar de alegria, de dor, sofrimento, sentimentos ambivalentes, angústia, 
desilusão. Contudo não são apenas partilhados valores, crenças e atitudes nas letras de músicas, mas também históricos de emoções associadas a esses valores e práticas (Abric, 2002; Campos \& Rouquette, 2005) por meio de processos sociocognitivos que se naturalizam nas experiências humanas, em suas relações sociais e individuais. Assim, ensina-se modelos de comportamentos e sentimentos que devem ou não ser manifestados, influenciando diretamente as representaçôes e práticas sociais.

\section{CONSIDERAÇŌES FINAIS}

Este estudo permitiu identificar alguns conceitos, valores e crenças relativas ao término de relacionamentos amorosos, presentes em conteúdos de letras musicais. Das quatro classes apresentadas, três delas apontaram sofrimento (em diferentes etapas) ao término da relação, tanto por parte de quem terminou a relação quanto de quem foi deixado.

As representaçôes sociais de término de relacionamentos amorosos presentes nas letras musicais trazem à tona um fenômeno no qual teoria e ação se articulam. As vivências amorosas estão claramente relacionadas com valores sobre como se deve sentir e agir diante de um contexto amoroso (neste caso, na situação de término), gerando, assim, representações sociais essencialmente voltadas a práticas afetivas. Isso vai ao encontro da própria definição de representação social proposta por Moscovici (1978), sendo ela uma forma de conhecimento prático, cuja função é elaborar comportamentos e formas de comunicação entre indivíduos. As letras musicais, como construtoras e difusoras de representações, elaboram esses comportamentos e modos de comunicação, além de naturalizar práticas, tornando-as consensuais, como se verificou neste estudo, por meio dos elementos representacionais presentes nas classes.

Assim, as letras musicais atuam em duplo sentido. São formadas por RS e as difundem, e influenciam RS já existentes, contribuindo com o caráter dinâmico e flexível dos conteúdos representacionais, o que torna esse fenômeno importante em investigaçóes psicossociais. Isso ocorre devido à natureza da música como objeto musical e social, formado por conteúdos representacionais que influenciam indivíduos e grupos que (re)agirão por meio de atitudes e comportamentos. Assim, as RS de temas presentes na música definem tanto a natureza do objeto musical quanto da relação do indivíduo com esse objeto.

Ademais, aponta-se aqui contribuição deste estudo na tentativa de articular a dimensão social e afetiva presente nas RS de término de relacionamentos amorosos por meio de letras musicais, uma vez que essa relação ocorre entre os 
afetos individuais e a vivência social da música. As letras musicais, ao mesmo tempo em que trazem sentimentos, histórias e valores que são reconhecidos pelos ouvintes, que passam a se identificar com as letras e canções, também influenciam parâmetros sociais que normatizam sentimentos predominantes em determinadas etapas dos relacionamentos. Nesse sentido, as letras de música atuam como uma expressão simbólica, ao apresentar em seu conteúdo representaçôes, formulações, tensões e sentimentos sobre determinados assuntos que fazem parte da vida cotidiana. Além disso, as letras musicais, quando em harmonia com a biografia dos indivíduos, passam a fazer uma conexão músicaafeto o que merece maiores investigações em pesquisas futuras.

Não obstante, o estudo apresenta limitações, tais como a necessidade de estudos com letras musicais com maior quantidade de intérpretes do sexo feminino, já que as letras de músicas analisadas são interpretadas, em sua maioria, por cantores do sexo masculino. Também se consideram relevantes estudos sobre esse tema em gêneros musicais diversificados, objetivando avaliar conteúdos convergentes e divergentes acerca das temáticas presentes nas letras. 


\section{REFERÊNCIAS}

Abric, J. C. (1998). A abordagem estrutural das representações sociais. In A. S. P. Moreira \& D. C. de Oliveira (Orgs.), Estudos interdisciplinares de representaçôes sociais. (pp. 27-38). Goiânia: AB.

Abric, J. C. (2002). L'approche structurale des représentations sociales: Développements récents. Psychologie et Société, 4, 81-103.

Alferes, V. R. (2004). Atração interpessoal, sexualidade e relações íntimas. In J. Vala \& M. B. Monteiro, Psicologia Social. (Vol. 2, pp. 125-158). Lisboa: Fundação Calouste Gulbenkian.

Andrade, J. R. (2009). Processo de luto diante da separação amorosa. (Trabalho de conclusão de curso). Universidade do Vale do Itajaí, Faculdade de Psicologia, Biguaçu-SC.

Arruda, A. (2007). Meandros da teoria: a dimensão afetiva das representações sociais. In Anais, 5 Jornada Internacional de Representaçôes Sociais, Brasília.

Bastos, G. de M. (2009). Jovem música sertaneja: a construção de marca dos artistas sertanejos contemporâneos. (Monografia), Universidade Federal de Brasília, Faculdade de Comunicação, Brasília.

João Bosco \& Vinicius (2008, setembro). Entrevista: João Bosco \& Vinicius fazem jovens perderem a vergonha do sertanejo. Entrevista concedida a Bruno Dias. Abril.com. Recuperado a partir de http://www.abril.com.br/noticia/ diversao/no_307161.shtml

Bronini, B. C., Esiquiel, K. C. da S. G., Lazarini, L., Parada, A. P. \& Almeida, T. de (2010). O rompimento dos relacionamentos afetivo-sexuais e suas resultantes. In Anais, 8 Jornada Apoiar: promoção de vida e vulnerabilidade social na América Latina: Reflexóes e Propostas, (pp.376-387). Recuperado a partir de https://www.academia.edu/1434895/O_ROMPIMENTO_DOS_ RELACIONAMENTOS_AFETIVO-SEXUAIS_E_SUAS_RESULTANTES

Budag, F. da E. (2009). Produção de sentidos nas músicas de RBD: o imaginário de amor e rebeldia. In Z. G. O. de Aquino \& B. D. Gil. (Orgs.), Estudos do discurso: diferentes perspectivas. (pp. 1-9). São Paulo: Ideia.

Camargo, B. V. (2005). ALCESTE: um programa informático de análise quantitativa de dados textuais. In A. S. P. Moreira, B. V. Camargo, J. C. Jesuíno \& S. M. Nóbrega (Orgs.). Perspectivas teórico-metodológicas em representações sociais. (pp. 511-539). João Pessoa: UFPB. 
Campos, P. H. F. \& Rouquette, M-L. (2003). Abordagem estrutural e componente afetivo das representações sociais. Psicologia: Reflexão e Crítica, 16(3), 435-445.

Cellard, A. (2008). A análise documental. In J. Poupart, J. P. Deslauriers, L. H. Groulx, A. Laperriére, R. Mayer, A. P. Pires, A pesquisa qualitativa: enfoques epistemológicos e metodológicos. (pp. 295-316). Petrópolis: Vozes.

Cunha, R. \& Cruz, M. C. S. (2011). Música na vida cotidiana. Revista Cientifical FAP, 7, 319-334.

Doise, W. (1985). Les représentations sociales: définition d'um concept. Connexions, 45, 243-253.

Ducatti, D. C. P. (2005). O luto pela separação nas relações amorosas. In G. Casellato (Org.), Dor silenciosa ou dor silenciada? (pp. 77-94). São Paulo: Livro Pleno.

Fernando \& Sorocaba (2008). Acústico. [CD]. São Paulo: Som Livre.

Fernando \& Sorocaba (2010). Bola de cristal. [CD]. São Paulo: Som Livre.

Goulart, K. C. S., Lazarini, L., Bronini, B. C., Parada, A. P., Pratta, E. M. M. \& Almeida, T. de. (2011). O término de um relacionamento amoroso: sentimentos predominantes e impactos na vida diária após a separação. In Anais do 3 Simpósio Brasileiro de Família e Desenvolvimento Humano (pp. 114116). Curitiba: Universidade Federal do Paraná.

Guedes, D. D., Monteiro-Leitner \& Machado, K. C. R. (2008). Rompimento amoroso, depressão e autoestima: estudo de caso. Revista Mal-estar e subjetividade, 8 (3), 603-643.

Guilherme \& Santiago (2008). Ao vivo em Goiânia. [CD]. São Paulo: Sony BMG.

Huron, D. (1999). Lecture 2: An instinct for music: Is music na evolutionary adaptation? In Annals New York Academy of Sciences. (pp. 43-61). New York: NYAS.

Ilari, B. (2006). Música, comportamento social e relações interpessoais. Psicologia em Estudo, 11(1), 191-198.

Janotti Júnior, J. S. (2004). Gêneros musicais, performance, afeto e ritmo: uma proposta de análise midiática da música popular massiva. Contemporânea, 2(2), 189-204. 
Jodelet, D. (1986). La representación social: fenómenos, concepto y teoria. In S. Moscovici, Psicología social 2: pensamiento y vida social. Psicología y problemas sociales. (pp. 470-494). Barcelona: Paidós.

Jodelet, D. (2001). Representações sociais: um domínio em expansão. In D. Jodelet (Ed.), As representaçôes sociais. (pp.17-29). Rio de Janeiro: Editora UERJ.

Jorge \& Mateus (2008). O mundo é tão pequeno afinal: ao vivo. [CD]. São Paulo: Universal Music Brasil.

Juslin, P. N. \& Sloboda, J. A. (2001). Musical and emotion: theory and research. Oxford: Oxford University Press.

Krumhansl, C. L. (1997). An exploratory study of musical emotions and psychophysiology. Canadian Journal of Experimental Psychology, 51, 336-352.

Maffesoli, M. (2007). O ritmo da vida. Rio de Janeiro: Record.

Marcondes, M. V., Trierweiter, M. \& Cruz, R. M. (2006). Sentimentos predominantes após o término de um relacionamento amoroso. Psicologia Ciência e Profissão, 1, 94-105.

Marcos \& Belutti (2009). Nosso lugar. [CD]. São Paulo: São Paulo: EMI.

Marcos \& Belutti (2011). Sem me controlar. [CD]. São Paulo: Sony Music.

Medina, C. A. (1973). Música e comunicação: um ensaio sociológico. Petrópolis: Vozes.

Moscovici, S. (1976). La psychanalyse: son image et son public. Paris: PUF.

Moscovici, S. (1978). A representação social da psicanálise. Rio de Janeiro: Zahar.

Moscovici, S. (1981). On social representations. In J. P. Forgas. Social Cognition perspectives on everyday understanding (pp. 181-209). London: Academic Press.

Moscovici, S. (1984). The phenomenon of social representations. In R. Farr \& S. Moscovici. Social representations. (pp. 3-70). Cambridge University Press.

Moscovici, S. (2012). A psicanálise, sua imagem e seu público. Petrópolis: Vozes.

Nóbrega, S. M., Fontes, E. P. G. \& Paula, F. M. S. M. de. (2005). Do amor e da dor: representaçôes sociais sobre o amor e sofrimento psíquico. Estudos de Psicologia, 22(1), 77-87. 
Rouquette, M. L. (2005). As representações sociais no quadro geral do pensamento social. In A. S. P. Moreira et al. Perspectivas teórico-metodológicas em representações sociais. (pp. 189-200). João Pessoa: Ed. UFPB.

Santana L. (2010). Ao vivo no Rio. [CD]. São Paulo: Som Livre.

Santos, D. O. (2010). Adolescentes e o sertanejo universitário: o gosto como uma atividade reflexiva. In Anais, 1 Simpósio Brasileiro de Pós-Graduandos em Música. (pp. 157-163). Rio de Janeiro: Unirio.

Sá-Silva, J. R., Almeida, C. D. de \& Guindani, J. F. (2009). Pesquisa documental: pistas teóricas e metodológicas. Rev. Brasileira de História \& Ciências Sociais, 1 (1), $1-15$.

Schlösser, A. (2014). O som do coração: influência da música nos relacionamentos amorosos. In T. de Almeida (Org.), Relacionamentos amorosos: o antes, o durante e $o$ depois (Vol. 2, pp. 97-112). São Paulo: Polo Books.

Silva, J. C. (2004). Eventos de música como estratégia de marketing (Monografia), Universidade Federal de Juiz de Fora, Faculdade de Comunicação Social, Juiz de Fora.

Sterberg, R. J. \& Grajek, S. (1984). The nature of love. Journal of Personality and Social Psychology, 47, 312-329.

Thaeme \& Thiago (2012). Ao vivo em Londrina. [CD]. São Paulo: Som Livre.

Vala, J. (1996). Representações sociais: para uma Psicologia social do pensamento social. In J. Vala \& M. B. Monteiro, Psicologia Social. (pp. 353-384). Lisboa: Calouste Gulbekian.

Vala, J. (2006). Representações sociais e psicologia social do conhecimento quotidiano. In J. Vala \& M. B. Monteiro. Psicologia Social. (pp. 457-502). Lisboa: Fundação Calouste Gulbenkian.

Wachelke, J. F. R. \& Camargo, B. V. (2007). Representaçōes sociais, representações individuais e comportamento. Rev. Interam. Psichol, 41(2), 379-390.

Zan, J. R. (2008). (Des)territorialização e novos hibridismos na música sertaneja. Revista Sonora, 1(2). Recuperado a partir de http://www.univerciencia.org/index. $\mathrm{php} /$ record/view/18595. 